\title{
O OUTRO CINEMA
}

Luiz Nazario

UFMG

\begin{abstract}
RESU M O
Um breve panorama da trajetória percorrida pelo desejo homossexual no cinema, de seu tímido despertar no cinema mudo alemão, passando pelo seu mascaramento em Hollywood e sua estilização no "cinema de arte" europeu, até a constituição de um assumido "cinema gay" nos oásis de liberdade do capitalismo avançado.
\end{abstract}

\section{PALAVRAS - CHAVE}

Cinema. Alteridade. Capitalismo avançado.

cinema sempre serviu de refúgio para os homossexuais que, sufocados pela realidade, projetaram suas fantasias sobre a tela: a cinefilia é um dos componentes fundamentais da cultura homossexual. O próprio cinema, enquanto indústria, sempre contou com grande staff de homossexuais ${ }^{1}$ e lésbicas. ${ }^{2}$ Contudo, até bem pouco tempo, o cinema apenas sugeria a existência da homossexualidade. A primeira dessas sugestões ocorreu em The Gay Brothers (1898), de Thomas Edison, onde dois homens dançam, alegremente, uma valsa. Na Suécia, o diretor Mauritz Stiller já escandalizava o público apenas com as tímidas sugestões de Asas (Vingarne, 1916), adaptado da novela Mikael (1902), de Herman Bang, que atualizou o mito do rapto de Ganimedes por Júpiter na paixão de um escultor por um jovem que adota como filho, também cobiçado por uma aristocrata russa. Mais focado no tema, e talvez o primeiro filme a abordar diretamente

\footnotetext{
${ }^{1}$ Basta recordar os diretores Friedrich Murnau, Sergei Eisenstein, James Whale, Joe Maxwell, Paul Powell, George Cukor, Vincente Minnelli, Delmer Daves, Jean Cocteau, Jacques Demy, André Techné, Luchino Visconti, Pier Paolo Pasolini, Andy Warhol, Paul Morrissey, Rainer Werner Fassbinder, Werner Schoeter, Derek Jarman, Gregori Araki e Gus Van Sant; os roteiristas Noel Coward, Truman Capote, Gore Vidal; ou os atores Ramon Novarro, Ivor Novello, Rodolfo Valentino, John Wayne, Gary Cooper, Randolph Scott, Cary Grant, Laurence Olivier, Robert Taylor, Charles Laughton, Montgomery Clift, Marlon Brando, James Dean, Sal Mineo, Rock Hudson, Anthony Perkins, Troy Donahue, Tab Hunter, Hayden Rorke, Joe Dalessandro, Brad Davis, Chris Sarandon, Billy Zane, Ian McKellen e Alan Cumming.

${ }^{2}$ Da diretora Dorothy Arzner e da figurinista Edith Head, que assumiam seu romance, às divas Greta Garbo, Lillian Gish, Marlene Dietrich, Nazimova, Joan Crawford, Jean Arthur, Agnes Moorehead, 'Dame' Judith Anderson, Kay Francis, Barbara Stanwick, Sandy Dennis, Judy Holiday, Tallulah Bankhead, Claudette Colbert, Dolores Del Rio, Janet Gaynor, Capucine e Madonna. Em The Hollywood Lesbians, Boze Hadleigh destaca as comediantes Patsy Kelly, Nancy Kulp e Marjorie Main, esta, famosa por seus papéis de mãe durona e esposa autoritária, e que teve um affair com Spring Byington, atriz que encarnava mães doces, frágeis e carinhosas.
} 
o desejo homossexual em situação foi Diferente dos outros (Anders als die Anderen, 1919), de Richard Oswald, realizado com a colaboração do pioneiro da sexologia, o judeu homossexual e comunista Magnus Hirschfeld. Neste filme, banido pela censura de Weimar e queimado pelos nazistas, hoje parcialmente restaurado através de fragmentos recuperados de diferentes arquivos, ${ }^{3}$ Conrad Veidt interpreta um violinista "diferente dos outros", apaixonado por um jovem aluno e que acaba se matando diante de uma chantagem, prática estimulada pelo Parágrafo 175 do Código Penal alemão, que considerava a sodomia como crime passível de prisão. ${ }^{4}$

Curiosamente, Hollywood apresentava nessa época maior abertura para o erotismo: nos épicos bíblicos de Cecil B. DeMille, a nudez era constante; nos filmes de David Grifftith, os homens beijavam-se na boca (assim como as mulheres entre si) para selar uma grande amizade; nas slapstick comedies, Lauren \& Hardy (O gordo e o magro) dormiam juntos na mesma cama. E em Salomé (Salome, 1923), de Charles Bryand, adaptado da peça de Oscar Wilde, a "outra" sensibilidade revelou-se nos gestos maneiristas do all gay cast exigido pela produtora e diva Alla Nazimova "para garantir fidelidade ao espírito da obra". 5 Tendo o marido Bryand como diretor e a amante Natasha Rambova (futura esposa de Rodolfo Valentino) como produtora, Nazimova pôde encarnar, aos quarenta anos, a adolescente perversa que enlouquecia Herodes (Mitchell Lewis) com sua dança dos sete véus e seus cachos de Medusa; a própria Rambova desenhou o espetacular adereço de pérolas gigantes que tremeluziam a cada meneio de sua cabeça, assim como os demais delirantes figurinos e cenários dessa extravagância inspirada nas ilustrações decadentistas de Aubrey Beardsley (1873-1898) para a primeira edição da obra de Wilde.

Na Dinamarca, uma nova adaptação do romance de Herman Bang, Mikael (1924), de Carl Theodor Dreyer, co-escrito por Thea von Harbou, retomou o tema do amor infeliz do artista por um aprendiz. No filme, esplendidamente fotografado por Karl Freund e Rudolph Maté, o renomado escultor Zoret (Benjamin Christensen) vive com seu protegido Mikael (Walter Slezak), até que a sedutora princesa Zamikoff (Nora Gregor) atrai o jovem para si, fazendo o rival mergulhar em amarga solidão. ${ }^{6}$

Ainda na Alemanha pré-nazista, Wilhelm Dieterle realizou um filme sobre um dos maiores tabus da sociedade: Geschlecht im Fesseln: Die Sexualität der Gefangenen (Sexo na cadeia: a sexualidade dos prisioneiros, 1928). Escrito por Herbert Juttke e Georg Klarenk, com base nos estudos de Franz Höllering e no relato Eros in Zuchthaus (Eros na prisão), do ex-presidiário Karl Plättner, o filme mostra a destruição de um casal comum pelo sistema penal. Com o marido Franz Sommer (Wilhem Dieterle) desempregado, Helene (Mary Johnson) é levada a vender cigarros num restaurante. Assediada por um cliente, ela pede socorro ao marido. Sommer empurra o atrevido, mas este bate a cabeça numa pedra, morrendo em conseqüência. $O$ réu é condenado a três anos de prisão. Helene ganha um emprego do empresário e ex-detento Rudolf Steinau (Gunnar Tolnæs)

\footnotetext{
${ }^{3}$ DIFFERENT from the Others, 2004.

${ }^{4}$ Para uma análise mais detalhada do primeiro cinema homossexual, ver KURTZ. Notas para uma história do cinema homossexual na era dos regimes totalitários.

${ }^{5}$ SALOMÉ, 1923.

${ }^{6}$ MICHAEL, 1924.
} 
que, solidário a Sommer, dedica sua vida a lutar contra as injustiças do sistema penal. Mas ele se apaixona por Helene que, no auge do desejo insatisfeito, bate às portas da cadeia gritando em vão por seu homem, depois vaga pelas ruas atrás de qualquer homem, terminando por entregar-se ao patrão. Por seu lado, Sommer envolve-se com o jovem presidiário Alfred (Hans Heinrich von Twardowski), que lhe declara amor durante uma missa. Ao sair da prisão, Sommer, agora "iniciado na sodomia”, e Helene, agora uma adúltera, não conseguem mais se relacionar, incapazes de assumir suas novas personalidades sexuais ou perdoar-se mutuamente pela satisfação "ilegal" de seus desejos no período do cárcere. A única solução que encontram é abrir o gás, e concluir o que o sistema prisional havia começado. Realizado segundo a estética da Nova Objetividade, combinando o sensacionalismo da denúncia (a estréia do filme em Berlim foi patrocinada pela Deutsche Liga für Menschenrecht - Liga Alemã dos Direitos Humanos) com o realismo da narrativa, marcada ainda pelo expressionismo das interpretações, o filme apenas sugere o desejo homossexual: uma noite, na prisão, um detento vicioso avança sobre a "carne nova" do prisioneiro recém-chegado, como uma cobra a dar o bote num inocente passarinho; outra noite, a consumação do desejo entre Alfred e Sommer é sugerida apenas por um gesto - uma mão estendida para outra que, correspondendo ao apelo, a aperta com firmeza. Mesmo permanecendo no campo das representações simbólicas, a ciranda de desejos entre os personagens é evidenciada pela expressiva pantomima dos atores, pelo que o filme foi proibido após o lançamento. ${ }^{7}$

Na Hollywood dos anos de 1930, a homossexualidade marcava presença nas telas sob a forma de alusões maliciosas, como no bizarro Just Imagine (1930), de David Butler. ${ }^{8}$ O lesbianismo - que despontou no filme alemão Senhoritas de uniforme (Mädchen in Uniform, 1931), de Leontine Sagan - é sugerido na deliciosa comédia Noite após noite (Night After Night, 1932), de Archie Mayo, quando, após uma noite de bebedeira, Mae West acorda na cama de outra senhora, que se transforma, depois desse contato, de puritana infeliz em alegre aventureira. Em Marrocos (Marrocos, 1933), de Joseph von Sternberg, Marlene Dietrich, vestindo smoking e cartola, beija uma garota da platéia na boca durante um número musical. $\mathrm{O}$ experimentalismo associado à cultura queer gerou o extraordinário curta-metragem Lot in Sodom (1933), de James Sibley Watson e Melville Webber. ${ }^{9}$ Imagens distorcidas de corpos nus, entregues a perversões apenas sugeridas, culminam na destruição da cidade pecaminosa, consubstanciando uma visão da homossexualidade psicologicamente carregada de culpa, mas esteticamente informada pelas vanguardas modernistas.

Os seriados de Tarzan sofreram a mesma sina de Flash Gordon: ${ }^{10} \mathrm{em}$ Tarzan, o destemido (Tarzan the Fearless, 1933), de Robert Hill, o magnético ex-campeão olímpico de natação

\footnotetext{
${ }^{7}$ Em 1996, com base numa cópia censurada em 1930, descoberta no acervo da Gosfilmofond, de Moscou; e na versão francesa existente na Stiftung Deutsche Kinemathek, de Berlim, que possuía as cenas ausentes da cópia russa, o filme pôde ser restaurado - com os intertítulos que faltavam reconstituídos a partir do texto original nos registros da censura alemã - pelo Filmmuseum München e pela Deutsche Kinemathek. ${ }^{8}$ NAZARIO. Monstros marcianos, p. 153-154.

9 O filme foi "redescoberto" por Barbara Hammer no ousado documentário Nitrate Kisses (1992).

${ }^{10}$ NAZARIO. Monstros marcianos, p. 154-155.
} 
Buster Crabbe pula de galho em galho com uma sunga de pele de leopardo que deixa suas nádegas completamente à mostra: muito mais que os atributos pouco explorados da mocinha Mary Brooks (Julie Bishop) é o corpo despido, com exuberante peitoral e coxas bem torneadas, do musculoso homem-macaco, o objeto de desejo valorizado pelo cinegrafista. Também o Tarzan, de Johnny Weissmüller (outro campeão olímpico de natação), usava em 1932 uma tanga de couro que deixava ver até partes das nádegas; também a Jane, de Maureen O'Sullivan, vestia um maiô que permitia a observação daquele ponto crucial onde nascem os seios. Em 1939, porém, e daí por diante, as ligas de moral obrigaram Tarzan a esconder seu umbigo "obsceno", e Jane a cobrir-se com uma malha inteiriça, até que em 1947, no auge da repressão à nudez dos personagens, esses pulavam de galho em galho com peles de leopardo até os joelhos.

As liberalidades dos anos de 1920-1930 foram reprimidas pelas Igrejas que, preocupadas com a moral, impuseram em Hollywood o Código Hays, ${ }^{11}$ impedindo que a simpatia do público fosse dirigida para o lado do crime, do erro, do mal e do pecado. $\mathrm{O}$ cinema devia mostrar modelos de vida corretos e respeitar as leis divinas, natural e humana. A exposição da violência era limitada ao máximo; desestimulava-se abordar suicídio, uso de drogas, rapto de crianças, crueldade contra animais; homossexualidade, sexo ilícito e adultério estavam proibidos: as instituições do casamento e do lar sendo sagradas, não se aceitavam relações casuais ou promíscuas. Danças, alusões, gestos e palavras obscenas estavam banidos, assim como a nudez de fato ou em silhueta.

Ainda na Inglaterra, Alfred Hitchcock mostrou em A dama oculta (The Lady Vanishes, 1938), de maneira natural, um casal de homens dormindo juntos e desnudos na mesma cama. Nesta altura, Hollywood já era regida pelo Código: a lei, a normalidade, a pureza racial, a felicidade conjugal e a santidade do lar deviam triunfar sobre o crime, a perversão, a miscigenação, o adultério e os valores da sarjeta. A idealização da vida sobrepujava e neutralizava os poderes da realidade. Contudo, pelo efeito mesmo dessa repressão, Hollywood acabou criando um universo que, por sua natureza anti-realista, era mais estimulante para a fantasia erótica - para toda fantasia - que a dessublimação repressiva que viria com o fim do Código.

\footnotetext{
${ }^{11} \mathrm{O}$ advogado presbiteriano Will Hays, presidente da Motion Picture Producers and Distributors of America - MPPDA, amigo do Presidente Herbert Hoover, convencido da má influência de Hollywood na sociedade americana, elaborou a lista "Dont's and Be Carefuls", dividida em duas partes: "Dont's" não permitia nudez, tráfico de drogas, escravidão branca, parto, cirurgias, primeira noite, casais na mesma cama, genitália infantil, beijos prolongados, perversão sexual, miscigenação; "Be Carefuls" deliberava sobre uso da bandeira americana, execuções legais, roubo de trens, vulgaridades. Sem apoio oficial, o que feriria os princípios democráticos, Hays organizou um mutirão ecumênico de igrejas cristãs, organizações judaicas, Legião da Decência, Liga Civil de Massachusetts e outras organizações da sociedade civil que impuseram o Código ao cinema. Adotado em 31 de março de 1930, sua aplicação passou a ser supervisionada em 1934 pela PCA (Production Code Administration) e vigorou em Hollywood sem alterações até 1956 (administrado pelo católico Joseph Breen até 1954) e com algumas mudanças até 1963. Os filmes aprovados recebiam um selo e os recusados perdiam os canais de distribuição da poderosa MPPDA. A desobediência custava aos produtores uma multa de 25 mil dólares. Ver PIRES, Thereza. Sexo, mentiras e Hollywood: o Código de Hays; DANIEL et al. Código de censura cinematográfice de 1930.
} 
Pois se o Código impedia a exploração de temas sexuais, isso também propiciava o desenvolvimento de um erotismo sublimado. Oficialmente proibido, a homossexualidade camuflava-se de rivalidade violenta, chegando às raias da mutilação e do assassínio, entre os cowboys Pat Garret (Thomas Mitchell) e Billy, the Kid (Jack Buetel), em O proscrito (The Outlaw, 1943), de Howard Hughes e Howard Hawks; de amizade inquestionável entre Calamity Jane (Doris Day) e Allyn Ann McLerie (Katie Brown), em Ardida como pimenta (Calamity Jane, 1953), de David Butler; de relação violentamente neurótica entre as rancheiras Vienna (Joan Crawford) e Emma Small (Mercedes McCambridge), em Johnny Guitar (Johnny Guitar, 1954), de Nicholas Ray; de amizade profunda entre Judah Ben-Hur (Charlton Heston) e Messala (Stephen Boyd) em Ben Hur (Ben Hur, 1959), de William Wyler. Nos filmes bíblicos, ousadias ainda maiores eram permitidas: seja pela fonte sagrada das suas inspirações, seja pela qualidade de "pecados" a serem punidos por Deus, como as relações lésbicas da rainha Bera (Anouk Aimée) em Sodoma e Gomorra (Sodom and Gomorrah, 1962), de Robert Aldrich, que excluiu, contudo, a homossexualidade masculina da cidade dos sodomitas.

$\mathrm{Na}$ sociedade moralista que impôs o Código, atores e cineastas homossexuais foram obrigados a adotar os padrões presumidamente heterossexuais do grande público. Nas décadas de 1940 e 1950, raras vezes, como em Chá e simpatia (Tea and Sympathy, 1956), de Vincente Minnelli, Hollywood ousou fazer de um homossexual o protagonista de um filme, e pôde ir além da compaixão. Temendo, por um lado, a censura e, por outro, o fracasso de bilheteria, os homossexuais de Hollywood adotaram a sexualidade majoritária como padrão estético e moral. Mesmo nos filmes baseados nas peças de Tennessee Williams, como Algemas de cristal (The Glass Menagerie, 1950), de Irving Rapper; De repente, no último verão (Suddenly Last Summer, 1959), de Joseph Mankiewicz; Gata em teto de zinco quente (Cat on a Hot Tin Roof, 1958), de Richard Brooks, ou O doce pássaro da juventude (Sweet Bird of Youth, 1962), de Brooks, os homossexuais aparecem sempre envoltos numa atmosfera mórbida e doentia.

No cinema, como na própria sociedade, o desejo homossexual viu-se impelido a refluir para as margens e para o subterrâneo: somente no cinema marginal e no cinema underground a homossexualidade pôde ser expressa e celebrada sem véus nem máscaras. Kenneth Anger, com Fireworks (1947), e Jean Genet, com Un Chant d'Amour (1950), introduziram os primeiros ensaios de homoerotismo no cinema. Nos anos de 1960 e 1970, os filmes "invisíveis" de Gregory Markopoulos, Paul Morrissey e Andy Warhol deflagraram outras transgressões estético-eróticas, das quais o corpo nu de Joe Dalessandro tornouse o próprio símbolo.

Na Itália, Pier Paolo Pasolini continuou essa tradição impondo no cinema comercial a nudez masculina integral, em O decameron (Il Decameron, 1971), Os contos de Canterbury (I Racconti di Canterbury, 1972) e As mil e uma noites de Pasolini (Il fiore delle Mille e una notte, 1974) - a chamada "Trilogia da vida". Apesar do escândalo, a "Trilogia" foi um grande sucesso, coincidindo com o erotismo obrigatório patrocinado pelo consumismo, pelo que Pasolini abjurou-a, produzindo um antídoto à permissividade estimulada pelo poder: Salò, ou Os 120 dias de Sodoma (Salò o Le 120 giornate di Sodoma, 1975).12

${ }^{12}$ NAZARIO. Todos os corpos de Pasolini. 
Ainda que tenha ousado mais que o cinema americano nesta área, o grande cinema europeu não soube promover uma imagem saudável do homossexual. Desde Roma, cidade aberta (1945), de Roberto Rosselini, que apresentou uma lésbica torturadora da Gestapo, até as obras de Federico Fellini e Ingmar Bergman, e ainda as de Pasolini e Luchino Visconti, nais quais os personagens que assumem o desejo pelo mesmo sexo aparecem invariavelmente associados à decadência. Este era mesmo o tema predileto de Visconti. Em seus filmes, a ruína do ser é sempre motivada por uma atitude sensual diante da vida. O sexo era, para ele, uma força destrutiva, que abalava lentamente o senso moral, e levava um caráter fraco à perdição. Nobre comunista, que dilapidou a fortuna da família produzindo arte contra a burguesia, Visconti celebrou a derrocada daquela classe em parábolas de coloração marxista que não dispensavam a decoração suntuosa, a roupagem esplêndida, as composições pictóricas e a estrutura melodramática. Preferindo filmar em interiores, fez seus personagens declamar diálogos torturantes em salões repletos de flores, entre serões e banquetes intermináveis. Visconti, que participou da Resistência, foi detido e quase fuzilado pelos fascistas, teve o sangue frio de filmar o julgamento sumário do prefeito Caruso, que o prendera, após a liberação, em Dias de glória (Giorni di Gloria, 1945); não poupou ao espectador a imagem chocante da cabeça do condenado esfacelada pelos tiros. Mas, a despeito da crueza deste documento histórico, o conjunto da obra narrativa de Visconti revela uma extrema vulnerabilidade à beleza e, sobretudo, à beleza selvagem do corpo masculino. A câmara de Visconti não resiste a registrar homens nus em duchas, banhos e orgias. Geralmente, ele encarrega um de seus personagens de contemplar, às escondidas, com a respiração entrecortada e a fronte banhada em suor, seu objeto secreto de desejo. Irresistivelmente seduzido pelo macho até o aterrorizante limite da perda de suas conquistas culturais, Visconti exteriorizou esse medo na constância com que adaptava novelas e romances de grandes escritores (Albert Camus, Dostoievski, Camilo Boito, Lampedusa, Thomas Mann). Teve, na juventude, o desejo de ser escritor, deixando uma novela inacabada, Angelo, quase um argumento para um filme neo-realista. Conservava uma maravilhosa biblioteca e sonhava em levar às telas Em busca do tempo perdido, de Marcel Proust. Como que para preservar suas aquisições culturais, Visconti manteve seu erotismo amordaçado, obrigando seus personagens decadentes a realizar, por procuração, aquela temida perda de status proporcionada pela homossexualidade. As criaturas de Visconti arruínam-se por paixão, como bodes expiatórios de um desejo revestido de temor sagrado.

Nas décadas de 1970-1980, o estigma milenar não deixou de impregnar mesmo as produções que se imaginavam quebrando tabus. O homossexual é um travesti afetado e efeminado em A gaiola das loucas (La Cage aux Folles, 1978) de Edouard Molinaro; O beijo da mulher aranha (1985), de Hector Babenco; Essa estranha atração (Torch Song Trilogy, 1988), de Paul Bogart. É um assassino ou uma vítima em potencial em À procura de Mr. Goodbar (Looking for Mr. Goodbar, 1977), de Richard Brooks; Parceiros da noite (Cruising, 1980), de William Friedkin; Caravaggio (Caravaggio, 1986), de Derek Jarman; Prick Up Your Ears (1987), de Stephen Frears. É um reprimido que, incapaz de realizar seu desejo, explode em violência, em Os pecados de todos nós (Reflexions in a Golden Eye, 1967), de John Huston; Furyo - em nome da honra (Merry Christmas, Mr. Lawrence, 1983), de Nagisa Oshima; Mishima (Mishima: A Life in Four Chapters, 1985), de Paul 
Schrader. É um complexado que se estiola numa ciranda de ciumeiras e despeitos em Os rapazes da banda (The Boys in the Band, 1970), de Friedkin; Domingo maldito (Sunday Bloody Sunday, 1971), de John Schlesinger; Nijinsky (Nijinsky, 1980), de Herbert Ross; O exército inútil (Streamers, 1983), de Robert Altman. É um heterossexual reprimido, que rebenta em histérica catarse, em Perdidos na noite (Midnight Cowboy, 1969), de Schlesinger; Cabaret (Cabaret, 1972), de Bob Fosse; Paixão selvagem (Je T'aime, Moi Non Plus, 1976), de Serge Gainsbourg; Um dia muito especial (Una Giornata Particolare, 1977), de Ettore Scola. É um neurótico enroscado nos traumas de infância, em Esquecer Veneza (Dimenticare Venezia, 1979), de Franco Brusati; Convite à viagem (Invitiation au Voyage, 1982), de Peter Del Monte; Coronel Redl (Colonel Redl, 1985), de István Szabó. É um autodestrutivo que mergulha numa espiral de degradação, em $O$ homem ferido (L'Homme Blessé, 1983), de Patrice Chéreau; Preto e branco (Noir et Branc, 1986), de Claire Devers; Meu marido de batom (Tenue de Soirée, 1986), de Bertrand Blier; Abaixo de zero (Less than Zero, 1987), de Marek Kanievska. É um masoquista impregnado de catolicismo doentio, em Dear Boys (1980), de Paul de Lussane; O quarto homem (De Vierde Man, 1983), de Paul Verhoeven; The Angelic Conversation (The Angelic Conversation, 1985) e War Requiem (War Requiem, 1989), de Derek Jarman.

Os clichês que cercam os homossexuais tornaram-se, graças às agressões generalizadas, parte integrante de sua psicologia existencial. $O$ círculo vicioso da arte que imita a vida e da vida que imita a arte impede uma visão "depurada" da homossexualidade. O horror causado pelo "amor que não ousa dizer seu nome" é tão profundo que mesmo os atores heterossexuais que interpretam homossexuais costumam ser estigmatizados. Christopher Reeve foi criticado ao trair sua imagem de super-homem para dar o melhor desempenho de sua carreira em Armadilha mortal (Deathtreap, 1982), de Sidney Lumet. Harry Hamlin ficou dez anos sem papel no cinema, aparecendo apenas na TV, depois de viver o homossexual que seduz um médico casado que se descobre bissexual em Fazendo amor (Making Love, 1982), de Arthur Hiller, filme que causou repulsa no público da época, muitos deixando as salas quando os dois homens se beijavam. E Brad Davis praticamente desapareceu das telas de cinema depois de ser o Querelle (Querelle, 1982) de Rainer Fassbinder.

Mesmo quando a homossexualidade era tratada abertamente, sem mistérios, e até com entusiasmo, como no cinema underground americano de Warhol e Morrissey; no Cinema Novo Alemão de Fassbinder e Werner Schroeter; nos filmes trash de Paul Bartel e Jonh Waters; naquele refinado cinema inglês que ousou recriar a vida, como em Memórias de um espião (Another Country, 1984), de Marek Kanievska; e Maurice (Maurice, 1987), de James Ivory; ou nos próprios filmes concebidos dentro da Gay Liberation, como nos filmes militantes de Rosa von Prauheim; em Taxi zum Klo (1981), de Frank Ripploh; Parting Glances (1986), de Bill Sherwood; ou Otra historia de amor (1986), de Américo Zárate, permanecia a sugestão do sofrimento onipresente.

Também às lésbicas de Imacollata e Concetta - L'altra gelosia (1979), de Salvatore Piscicelli; Mystère Alexina (1985), de René Féret; ou Vera (1987), de Sérgio Toledo, o destino só reservava o drama, o crime, a tragédia. Entre 1961 e 1976, em 32 filmes que abordaram o tema, 13 personagens homossexuais matavam-se, 18 eram mortos por seus 
amantes e um era castrado. Até o fim dos anos de 1980, todos os espelhos cantavam, em uníssono, que era impossível ser, ao mesmo tempo, homossexual e feliz.

Contudo, desde a revolta de Stonewall, a 28 de junho de 1969, que desencadeou os movimentos pelos direitos dos homossexuais nos Estados Unidos, passeatas multicoloridas nas principais cidades do mundo vêm proclamando o "orgulho gay", e a cada ano o número de manifestantes cresce em progressão geométrica. Lentamente, a cultura homossexual realizou grandes conquistas: quando Lamont Johnson realizava That Certain Summer (1972), o primeiro telefilme a contar uma história de amor entre dois homens, recebeu da emissora a advertência de que os amantes "não deveriam jamais se tocar e seus olhos jamais se cruzar". Hoje, um seriado da TV inglesa como Queer as Folk (2000-2005) pode apresentar cenas quase explícitas de coitos homossexuais, e alguns canais a cabo já apresentam programação exclusivamente gay.

Contudo, a AIDS irrompeu como uma verruga na face risonha do mundo que se liberava. Desde 1981, quando foi identificada como "peste gay", até 2001, quando o perfil de suas vítimas mudou radicalmente, passando às camadas mais pobres desinformadas da sociedade, cerca de 22 milhões de pessoas morreram vítimas dessa doença. O preconceito agravou a catástrofe nas periferias do mundo e a AIDS passou a ser cada vez mais associada a uma "peste africana": em 2000, dos 34,2 milhões de portadores do vírus HIV, 24,5 milhões encontravam-se na África, numa proporção de um contaminado para cada cinco habitantes.

No início da epidemia, os cineastas de Hollywood, que já haviam encontrado todo tipo de obstáculo para abordar a homossexualidade, continuaram por um bom tempo sem ação para abordar a AIDS. Barbra Streisand tentou em vão adaptar The Normal Heart, de Larry Kramers (a novela só seria transformada em filme para TV pela BBC em 1991, sob a direção de Nigel Finch); o mesmo se passou com John Schlesinger ao tentar adaptar The Lost Language of Cranes, de Davi Leavit; e o dramaturgo Craig Lucas só conseguiu realizar o primeiro filme de grande orçamento sobre a AIDS, Meu querido companheiro (Longtime Companion, 1990), de Norman René, após seis anos de respostas negativas dos produtores e inúmeras recusas de atores temerosos de comprometerem suas carreiras.

Depois da negação sistemática, Hollywood acabou encontrando uma maneira errada - de abordar o novo fenômeno, fazendo propagar associações de advertência entre o sexo e a morte, aludindo à doença através da metáfora dos parceiros sexuais suspeitos, perigosos, maníacos, assassinos, de preferência femininos. Ellen Barkin, em Vítimas de uma paixão (Sea of Love, 1989), de Harold Becker; Kim Bassinger em Desejos (Final Analysis, 1992), de Phil Joanou; Madonna, em Corpo em evidência (Body of Evidence, 1992), de Uli Edel; Rebecca DeMornay, em A mão que balança o berço (The Hand that Rocks the Cradle, 1992), de Curtis Hanson; Jennifer Jason Leigh, em Mulher solteira procura (Single White Female, 1992), de Barbet Schroeder; e Sharon Stone, em Instinto selvagem (Basic Instinct, 1992), de Paul Verhoeven, assumiram o triste papel do HIV.

Sob a proteção dessas advertências moralistas, os cineastas puderam ousar mais, chegando aos limites da pornografia, como na cena de Instinto selvagem em que Sharon Stone descruza as pernas na delegacia e exibe sua vagina - cena tão vulgar que logo foi parodiada em Top Gang 2 - a missão (Hot Shots - Part Deux, 1993) de Jim Abrahams; e em 
Distração fatal (Fatal Instinct, 1993), de Carl Reiner. A atriz justificou-se declarando que o diretor prometera uma iluminação especial, que não permitiria ao espectador ver seu sexo; ela teria ficado "furiosa" ao ver no filme a cena bem iluminada. Mas se seu sexo não seria visto, por que rodou sem calcinha? O fato é que, com o fim do star-system, os astros e estrelas tiveram de ceder à pressão dos produtores, dos diretores e do público, prestando-se a todas as baixezas. Kenneth Anger não precisaria mais contatar fofoqueiros e paparazzi se quisesse atualizar as edições de seu Hollywood Babylon: a Babilônia de Hollywood saltou dos bastidores para o palco, e exibe-se com vulgaridade e glamour, nas grandes e pequenas telas.

Não só as mulheres foram monstrificadas através de uma sexualidade exuberante e fatal. Surgiram também homens aparentemente normais, mas cuja aproximação sexual colocaria em risco a vida de suas esposas e amantes, como os maridos e sedutores desequilibrados interpretados por Patrick Bergin, em Dormindo com o inimigo (Sleeping with the Enemy, 1991), de Joseph Ruben; Kevin Spacey, em Jogos de adultos (Consenting Adults, 1992), de Alan J. Pakula; Donald Sutherland em Desejo assassino (Benefit of the Doubt, 1992), de Jonathan Heap; Don Johnson, em Tão culpado como o pecado (Guilty as Sin, 1993), de Sidney Lumet; William Baldwin, em Sliver (Invasão de Privacidade, 1993), de Kevin Meyer; e Michael Douglas, em Um dia de fúria (Falling Down, 1993), de Joel Schumacher; Robert De Niro na refilmagem de Cabo do medo (Cape Fear); Alec Baldwin, em The Juror; ou Antonio Banderas em Nunca fale com estranhos (Never Talk to Strangers). Nesses filmes, a heroína se apaixona pelo sedutor desconhecido e tem relações sexuais com ele, antes de descobrir que no corpo desejável reside a alma de um cafajeste, de um assassino ou coisa pior.

Porém, os "homens fatais" dos thrillers sexuais confundem-se com o papel tradicional dos "machistas" (como o de Alec Baldwin na nova versão de A Street Car Named Desire), não passando de um exagero de características consideradas "naturais". Foram, pois, as estrelas que transmitiram melhor a mensagem de perigo mortal representado pela promiscuidade: tradicionalmente associada ao desejo e à morte, a femme fatale passou a encarnar a AIDS. Queria-se advertir os homossexuais dos perigos da promiscuidade, sem que o "contagiante" erotismo gay fosse explicitado. Mas esses filmes foram entendidos pelo grande público como um novo modelo de erotismo a ser seguido. As associações mórbidas entre o sexo e a morte dominaram o imaginário coletivo. A própria cena homossexual degradou-se de tal forma que os sobreviventes da AIDS aderiram em peso à estética SM, com piercings, tatuagens, uniformes de couro, cabelos raspados e acessórios de tortura. A um homossexual quase já se proíbe viver seu Eros com ternura: todos devem passar pela "fase sadomasoquista". A forma estética mais acabada desse erotismo apareceu fixada no Girlie Show de Madonna e na bacanal gelada de De olhos bem fechados (Eyes Wide Shut, 1999), de Stanley Kubrick. Sua conseqüência mais desastrosa foi o crescimento irreprimível da AIDS.

Da pequena cena homossexual, a agressividade erótica imigrou para a grande cena heterossexual e as fantasias erótico-fascistas de Tom of Finland, antes restritas aos fetichistas, espalharam-se por toda a sociedade, com Tiazinhas de TV usando biquinis de couro, máscaras e chicotes para "torturar" adolescentes cheios de espinhas em 
programas de auditório. O medo da AIDS misturou-se ao medo da fêmea "irresistível", e de tal modo que as campanhas de prevenção à doença assumiram o caráter, por um lado, de propaganda gratuita para as indústrias de camisinha e, por outro, de aventuras transgressivas e tórridas entre homens e mulheres desconhecidos supostamente munidos de preservativos. $^{13}$

Uma resposta aos thrillers sexuais de Hollywood foi dada por Amor e restos humanos (Love Ë Human Remains, 1993), de Denys Arcand, em que corpos de mulheres aparecem jogados no lixo, sob as pontes, nos ermos subúrbios de Montreal, com os lóbulos das orelhas rasgados, marca registrada de um assassino serial que cultiva a triste mania de arrancar brincos ao atingir o orgasmo homicida. No filme, qualquer um dos personagens - saídos da peça Unidentified Human Remains and the True Nature of Love, de Brad Fraser, que assinou o roteiro - pode ser o assassino psicopata. Seguindo a mania da época, tampouco este autor evitou o uso da pior metáfora da AIDS: o assassino serial como símbolo material da doença. Todos transam eventualmente sem preservativo; todos podem estar contaminados, transmitindo a morte em cada assalto sexual. As relações entre os personagens e os crimes que assolam a cidade alternam-se e confundem-se, até a descoberta do assassino, que coincide com a revelação de um teste positivo de AIDS. É o que inquieta na metáfora do assassino serial: mesmo quando empregada por escritores, dramaturgos ou roteiristas sem preconceitos, ela não deixa de trair suas origens militaristas - todas as vítimas do serial killer são mulheres; somente elas são "restos humanos". E não é por causa do uso de brincos, já generalizado também entre os homens. As causas são mais profundas.

Ao mesmo tempo em que a AIDS tornou o sexo "impraticável" do ponto de vista estético, moral, político, psicológico e social, o advento da pornografia de massa realizou um corte radical, oferecendo como modelo o sexo mecânico e o sexo virtual, destituídos de qualquer implicação estética, moral, política, psicológica ou social. A propaganda consiste em vender a idéia de que "a vida continua", de que o sexo pode e deve continuar sendo praticado, como se nada tivesse acontecido: basta colocar a camisinha, isto é, a culpa. Nunca como agora a cultura de massa exibiu tantos corpos nus e excitantes: justamente porque o erotismo perdeu sua força subversiva. A liberação sexual não suscita mais nenhuma liberação social e política. Mas não foi apenas ao erotismo espontâneo que a AIDS pôs um fim: foi à própria perspectiva da revolução total tal como a concebia Herbert Marcuse. ${ }^{14} \mathrm{~A}$ indústria cultural encontrou nesse impasse sua melhor ocasião de

\footnotetext{
${ }^{13}$ Numa "campanha de prevenção à AIDS" para a organização Red Hot, Bruce Weber fotografou casais e grupos diversos atracados em orgias selvagens na praia, onde ninguém parecia usar camisinhas. Em outra "campanha de prevenção à AIDS", um gibi de Paulo Garfunkel e Libero Malavoglia, financiado pelo Colégio Objetivo, foi distribuído para 4.500 presidiários da Casa de Detenção de São Paulo (17\% já infectados), entre os quais a AIDS propaga-se basicamente através de agulhas contaminadas por rodadas de drogas injetadas na veia ou relações homossexuais (82\% dos travestis detentos são soropositivos): o herói "Vira Lata" abastece-se de camisinhas antes de atacar sexualmente a empregada que faz faxina nua e a filha do patrão que aparece de pernas abertas num encarte que se pode afixar na cela. Os pais de família que se cuidem: libertados, os presidiários estarão prontos para realizar essas fantasias. A única esperança é que não se esqueçam da cartilha e usem camisinhas antes das curras, como já o exigiu a heroína estuprada em Kika (1993), de Pedro Almodóvar.

${ }^{14}$ Ver MARCUSE. Eros e civilização; MARCUSE. A ideologia da sociedade industrial.
} 
provar o quanto é liberal e tolerante. Tendo a AIDS apagado o horizonte da revolução total dos instintos, a sociedade de consumo pode demonstrar sua tolerância para com os homossexuais, e até casamentos gays são agora oficiados sem causar terremotos.

Sob o efeito da AIDS e da pornografia de massa, Hollywood foi levada a rever sua posição sobre os gays. Um Oscar foi concedido a Filadélfia (Philadelphia, 1993), de Jonathan Demme, protagonizado por Tom Hanks e Antonio Banderas, centrado no drama do amante que agoniza de AIDS. Embora não haja nenhum erotismo no filme, foi a partir da comoção que ele produziu - o Love Story dos anos da peste - que a sociedade tomou consciência da existência de homossexuais que contraem a AIDS e continuam a viver sua vida condenada, agora, não apenas por Deus, pela sociedade e pela família, como também pela própria "vida". Desde então, o cinema passou a demonstrar piedade ecológica em relação aos gays, essa "espécie em extinção". Surgiram "filmes simpatizantes" (o "S" de "GLS"), nos quais o casal straight é cercado por personagens secundárias gays, que conquistam o público tolerante com sua "doçura", "inteligência" e "sensibilidade". Os ex-perversos, convertidos em "seres de luz", foram integrados ao mundo normal, mantendo, é claro, seu erotismo na sombra.

Ao mesmo tempo tornou-se possível a existência de uma empresa como a Strand Releasing, de Marcus $\mathrm{Hu}$, especializada em produzir e distribuir filmes com temática homoerótica. Se até fins dos anos de 1980 a produção anual destes filmes nos EUA e na Europa era de apenas 4 ou 5 títulos, a partir dos anos de 1990 ela chega a 50 ou 60 títulos, crescendo anualmente, contando com um público fiel cada vez mais "assumido" que torna a produção rentável. Com a integração econômica dos homossexuais na sociedade de consumo, o mercado homossexual tende a fortalecer-se cada vez mais.

A atitude dos astros de Hollywood passou a ser mais afirmativa. Marjorie Garber observou, em Vice-versa, que os atores de Hollywood até cultuam a bissexualidade para atrair maior número de fãs. A tendência firmou-se quando ídolos heterossexuais, como Mel Gibson e Kevin Costner, deixaram-se filmar em nu dorsal. Quando o nu dorsal generalizou-se, alguns astros resolveram ousar o nu frontal: Sylvester Stallone, em O demolidor (Demolition Man, 1993); Bruce Willis, em The Color of the Night (1994); Cuba Gooding em Jerry Maguire (Jerry Maguire, 1996). O novo passo foi aceitar papéis de homossexuais: Tom Hanks namora Antonio Banderas em Filadélfia (Philadelphia, 1993), de Jonathan Demme; Leonard DiCaprio dorme com David Thewlis em Eclipse de uma paixão (Total Eclipse, 1995), de Agnieszka Holland; Brad Pitt, Tom Cruise e Antonio Banderas mantêm uma atração sexual recíproca em Entrevista com o vampiro (Interview with a Vampire, 1995), de Neil Jordan; Robin Williams é o marido de Nathan Lane em A gaiola das loucas (The Birdcage, 1996), de Mike Nichols.

No violento policial O chacal (The Jackall, 1998), de Michael Caton-Jones, Bruce Willis, no papel de um terrorista, disfarça-se de sedutor gay para envolver um gay de verdade, o qual beija na boca. Logo Tom Selleck e Kevin Kline quebraram, em In $\mathscr{E}$ Out (In $\mathcal{E}$ Out, 1997), de Frank Oz, o mais sagrado dos tabus: não o do beijo na boca entre dois homens, mas o do beijo na boca entre dois ícones da masculinidade, isto é, o "beijo cinematográfico" que Hollywood reservava apenas ao astro e à estrela da tela. Nos dois casos, os contextos particulares da farsa policial e da comédia justificaram as transgressões pioneiras. Essa tímida liberação nos grandes estúdios estimulou Rupert Everett, Billy 
Zane, Ian McKellen, Anne Heche e Ella DeGeneris a declararem sua homossexualidade, desafiando a velha moral de Hollywood. ${ }^{15}$ Mas essas revelações não costumam favorecer os astros emergentes, cujas fãs, majoritariamente femininas, sentem-se traídas, ao saberem a verdade, em suas fantasias eróticas. Everett e Zane, assim como galãs que ousaram interpretar papéis de homossexuais - Mathew Broderick, depois de Torch Song Trilogy (1988), de Paul Bogart; ou Patrick Swayze (ao lado de Wesley Snipes e John Leguizamo), depois de To Wong Foo, Thank you for all! Julie Newmar (1995), de Beeban Kidron - ainda tiveram suas carreiras "congeladas".

Ao obrigar a sociedade a retirar a homossexualidade da clandestinidade na tentativa de controlar a epidemia, a AIDS facilitou a explosão das sexualidades reprimidas, fazendo florescer um vigoroso cinema gay e lésbico, sustentado pelo crescente "mercado gay". Vivemos, desde os anos de 1990, o boom da produção com temática homossexual, de formato e qualidade variada: de melodramas pornográficos a exercícios explícitos de sadomasoquismo, de comédias baratas a obras-primas cinematográficas. Essa produção encontra vazão num mercado paralelo formado por mais de 100 festivais de cinema GLS $^{16}$ ou GLTB $^{17}$ em todo o mundo, festivais que funcionam como importante reconhecimento de identidade para seu público específico, mas que também revelam para um público mais amplo o outro cinema. ${ }^{18}$

\footnotetext{
${ }^{15}$ Somente aos 75 anos Tab Hunter assumiu a homossexualidade numa entrevista para o New York Times, logo revelada em suas memórias: Tab Hunter Confidential - The Making of a Movie Star (2005). Quando jovem, trabalhando numa escola de equitação, conheceu o ator Dick Clayton, que o apresentou ao agente Harrry Wilson, representante de Rock Hudson. Olhando o louro que esbanjava energia, mas possuía um "mau nome" (Arthur Gelien), Wilson disse: "We've got to tab you something" ("temos que arrumar alguma coisa pra você"), acrescentando o hunter (caçador), pois combinava com cavaleiro. Pouco antes de estrear Battle Cry (1855), de Raoul Walsh, que o tornaria novo sex symbol em Hollywood, a revista Confidential publicou matéria sobre uma "festa do pijama" ocorrida cinco anos antes, quando a polícia, numa batida no Walnut Park, nada teria encontrado além de uma "baderna entre pessoas do mesmo sexo". A maldosa nota não chegou à grande mídia, e a carreira de Tab Hunter não foi arruinada, mas ele teve que passar a sair em público com "noivas" como Debbie Reynolds, Dorothy Malone e Natalie Wood, enquanto na intimidade mantinha um complicado romance com Anthony Perkins. Ver PIRES. Tab Hunter: antes tarde do que nunca.

${ }^{16}$ Gays, Lésbicas e Simpatizantes.

${ }^{17}$ Gays, Lésbicas, Transgêneros e Bissexuais.

${ }^{18}$ No cinema brasileiro, observou-se o mesmo fenômeno. Num levantamento de 127 filmes brasileiros realizados entre 1923 e 1996, Antônio Moreno mostrou, em A personagem homossexual no cinema brasileiro, como o homossexual foi severamente ridicularizado no cinema nacional, onde os personagens gays quase sempre aparecem como "alienados". É o gay-clown, destinado a fazer a platéia rir, que desmunheca em roupas espalhafatosas, gane em voz de falsete, anda como manequim em passarela e apresenta comportamento falso e traiçoeiro. Já numa comédia do cinema mudo, Augusto Anibal quer casar (1923), de Luiz de Barros, um caipira casa-se com um travesti e, ao descobrir o "engano", sai em disparada. Nas chanchadas da Atlântida dos anos de 1940 e 1950, o travesti ganha uma caracterização grotesca e assexuada, como em Carnaval no fogo (1949), com Oscarito como Romeu e Grande Otelo como Julieta; ou em Carnaval Atlântida (1952), em que Oscarito novamente se traveste. Nos anos de 1960, Walter Hugo Khouri usa, como em Noite vazia (1964), o lesbianismo para excitar o público masculino. No cinema undergound surgem imagens mais complexas da homossexualidade, como em Matou a família e foi ao cinema (1967) e A família do barulho (1970), de Júlio Bressane; ou Orgia, ou o homem que deu cria (1970), de João Silvério Trevisan - filmes invariavelmente censurados. Já o Cinema Novo encampado pela Embrafilme e o cinema comercial continuaram a mostrar gays efeminados ou delinqüentes, como
} 
Um dos mais antigos é o Festival Internacional do Filme com Temática Homossexual "De Sodoma a Hollywood" de Turim, em sua 23a edição em 2008. ${ }^{19}$ Em 1995, em Israel, ultraortodoxos liderados pelo rabino Yitzhak Kulitz protestaram contra a realização do Festival de Cinema Homossexual e Lésbico promovido pela Cinemateca de Jerusalém, mas sua diretora Lia Van Leer ignorou as ameaças e manteve a programação. Em 1999, foi criado o Festival de Cinema Gay e Lésbico de Miami. Em São Francisco, onde o Gay Pride Day leva metade da população às ruas, tem lugar o San Francisco International Lesbian \& Gay Film Festival. Em Berlim, na Berlinale, ocorre a mostra Panorama, a mais concorrida de todas. O Mix - New York Lesbian \& Gay Experimental Film/Video Festival; o Festival FCGLL de Lisboa; o Festival Gay e Lésbico de Londres; Festival de Filmes GLS Inside Out de Toronto e, no Brasil, desde 1992, o Mix Brasil - Festival de Manifestação das Sexualidades, dirigido por André Fischer e Suzy Capó, são outros importantes festivais de cinema GLS. O mais peculiar dos festivais é o de Tóquio, obrigado a comprar as cópias dos filmes programados, já que a censura japonesa proíbe a mostra de genitais: seus organizadores têm de imprimir tarjas pretas sobre os órgãos e editar as cenas de sexo explícito, para uma platéia que ainda permanece majoritariamente feminina. Em 2004, durante a 3ํㅡㄹ Conferência Norte-Americana para Lésbicas, Gays, Bissexuais, Transgêneros Mulçumanos e Simpatizantes, em Los Angeles, ocorreu a primeira mostra de filmes gays muçulmanos, promovida pela Fundação Al-Fatiha, baseada nos EUA, dedicada a apoiar homossexuais islâmicos. Graças a esses festivais, filmes mais bem produzidos ganharam o circuito alternativo, alguns arrecadaram fortunas e forçaram, pela lógica do mercado, a introdução da temática também em seriados de TV, como $\mathrm{Oz}$ (1997); O sexo e a cidade (Sex and the City, 1998); Will e Grace (Will Ë Grace, 1998); Os assumidos (Queer as Folk, 2000) - produzida ao alto custo de 1 milhão de dólares por

em Rainha diaba (1974), de Antonio Carlos Fontoura. Uma bela exceção é Estranho triângulo (1970), de Pedro Camargo, onde o estudante Durval (Carlo Mossy) torna-se amante do milionário Duncan (André José Adler) para subir na vida, até que o milionário casa-se por conveniência e a esposa passa a dividir o rapaz com o marido. Nos anos de 1980, os homossexuais são vistos com mais respeito, como em Pixote, a lei do mais fraco (1981) e O beijo da mulher aranha (1985), de Hector Babenco; Vera (1987), de Sérgio Toledo, e A menina do lado (1987), de Alberto Salvá. Na década de 1990, se Matou a família e foi ao cinema (1991), de Neville de Almeida, desmoraliza os homossexuais, Jenipapo (1995), de Monique Gardenberg, dedica-lhe um tratamento mais delicado. E em Madame Satã (2002), de Karim Ainouz, e Cazuza - o tempo não pára (2004), de Walter Carvalho e Sandra Werneck, uma homossexualidade mais realista começa a ganhar o cinema nacional.

${ }^{19}$ A idéia do Festival surgiu em 1986, com a repercussão positiva do filme em vídeo Dalla vita di Piero (1981), de Ottavio Mai e Giovanni Minerba, convidado para vários festivais internacionais. O projeto obteve a colaboração da Província de Turim e da Região do Piemonte e, em 1988, o Festival pôde reconhecer o talento de Gus Van Sant premiando seu filme de estréia, Mala Noche. Em 1989, apresentou a pré-estréia mundial de The Rainbow, de Ken Russell. Em 1990, exibiu a versão integral de Derek Jarman. Em 1990 e 1991, o Festival encontrou inesperado sucesso com mostras do cinema mudo com temática gay. Desde então, realiza, a cada ano, uma grande retrospectiva em homenagem a um ícone gay do cinema: Greta Garbo, Jean Genet, William Burroughs, Mae West, James Dean, Rock Hudson, Betty Page, Dalida, Joe Dallesandro, Marlene Dietrich, Rainer Fassbinder, Marilyn Monroe, Jean Cocteau. Na edição de 1995, o Festival lançou o catálogo Da Sodoma a Hollywood: Fotogrammi Sovversivi Attraverso Cento Anni di Cinema, com estudos de David Robinson, Richard Dyer, Vieri Razzini, Mariuccia Ciotta, Fabio Bo. Festival Internazionale di Film con Tematiche Omosessuali "Da Sodoma a Hollywood" di Torino. 
capítulo, e sendo vista por 4,5 milhões de espectadores em sua estréia; A sete palmos (Six Feet Under, 2001); The L Word (2004) e Linha de beleza (2007), onde personagens homossexuais podem satisfazer seus desejos em representações realistas.

O amor entre homens, cada vez menos tabu, obteve sua consagração cinematográfica em O segredo de Brokeback Mountain (Brokeback Mountain, 2005), de Ang Lee, indicado a 8 Oscars, e vencedor em Melhor Direção, Música Original e Roteiro Adaptado, agraciado ainda com 76 outros prêmios em todo o mundo. Antes deste novo marco, "ninguém queria gastar dinheiro com isso; agora Hollywood vê que é possível fazer dinheiro com um filme sobre homossexuais e isto abre as portas para outros projetos", declarou Patricia Nell Warren, autora do romance The Front Runner (1974) sobre dois atletas que se amam. ${ }^{20}$

Mas se a cultura pós-gay ${ }^{21}$ pode ser absorvida pela cultura de massa, também produz uma crescente homofobia em bilhões de jovens que, convictos de serem machos, sentemse ameaçados pelo imaginário homossexual liberado (machos penetrados por machos penetrando outros machos...) que solapa a segurança de egos fragilizados pela própria cultura de massa. No fundo das consciências, a intolerância permanece imutável, e agravada nas ditaduras de direita e esquerda e nos países islâmicos que sucumbem ao fundamentalismo homofóbico em expansão desde a Revolução Iraniana de 1979. Se em 1990 a Assembléia Geral da OMS, vinculada à ONU, retirou a homossexualidade da lista de distúrbios mentais, ainda hoje, em oitenta países, aprisionam-se homossexuais e, em nove deles - Afeganistão, Arábia Saudita, Emirados Árabes Unidos, Irã, Mauritânia, Nigéria, Paquistão, Sudão e Yemen - a homossexualidade é punida com a morte. ${ }^{22}$

Somente em poucos redutos das sociedades capitalistas avançadas, e graças à existência de um novo mercado gay, tornou-se possível uma vivência praticamente normal ${ }^{23}$ da homossexualidade. Nos EUA, sobretudo, onde, em 1998, o mercado gay movimentou cerca de 340 bilhões de dólares, a integração econômica dos homossexuais na sociedade de consumo permite que as imagens dos relacionamentos sexuais e afetivos entre homens extravasem os limites circunscritos dos guetos, ganhando o espaço público. Os tabus foram quebrados nos segmentos mais cultos da sociedade e em ramos significativos da produção audiovisual. Mas o longo caminho percorrido pelo desejo homossexual em sua luta por representações visuais libertas de estereótipos degradantes - mesmo dentro da própria cultura homossexual - não terminou. A intolerância é cíclica e, se hoje ela faz uma pausa na perseguição em alguns oásis do capitalismo avançado, não há sinal de redenção definitiva: o que triunfa nas telas é uma forma tolerada de relacionamento restrito a homossexuais e não a homossexualidade livre para ser assumida por qualquer um na meta do ideal libertário da humanidade.

\section{(4)}

\footnotetext{
${ }^{20}$ LAVINE. Brokeback lança tendência gay em Hollywood.

${ }^{21}$ Ver FRESSIA. Acerca de la literatura gay.

${ }^{22} \mathrm{http}$ //www.ilga.org/statehomophobia/Homofobia_do_Estado_ILGA_07.pdf.

${ }^{23}$ Segundo o termo com que Andrew Sullivan definiu a "agenda política da homossexualidade" no fim do século XX. Ver SULLIVAN. Praticamente normal.
} 


\section{RÉ S U MÉ}

Un bref panorama de la trajectoire parcourue par le désir homosexuel au cinéma, de son timide réveil au cinéma muet allemand, en passant par son déguisement à Hollywood et sa estilisation au "cinéma d'art" européen, jusqu'à la constitution d'un assumé "cinéma gay" dans les oasis de liberté du capitalisme avancé.

\section{Mots-CLEFS}

Cinéma. Altérité. Capitalisme avancé.

\section{REFERÊNCIAS}

DANIEL, R. et al. Código de censura cinematográfico de 1930. Versión textual del célebre código de censura Hays en Hollywood. Cinemateca, Montevideo, n. 19, p. 41-42, mar. 1979. DIFFERENT from the Others. Director: Richard Oswald. Gay-Themed Films of The German Silent Era. Restored by Film Museum München. Kino Vídeo, 2004. DVD.

FESTIVAL INTERNAZIONALE DI FILM CON TEMATICHE OMOSESSUALI "DA SODOMA A HOLLYWOOD” DI TORINO. Disponível em: < http://www.tglff.com/ 2007/index.htm $>$.

FRESSIA, Alfredo. Acerca de la literatura gay. Agulha, Fortaleza, São Paulo, n. 20, jan. 2002. Disponível em: <http://www.revista.agulha.nom.br/ag20fressia.htm > . Acesso em: $1^{\circ}$ ago. 2007.

KURTZ, Adriana. Notas para uma história do cinema homossexual na era dos regimes totalitários. Menemocine, $1^{\circ}$ jun. 2001. Disponível em: <http://www.mnemocine.com.br /cinema/historiatextos/adrianacinehomo.htm>. Acesso em: 19 maio 2008.

LAVINE, Marc. Brokeback lança tendência gay em Hollywood. Folha on line, São Paulo, $1^{\circ}$ mar. 2006. Folha Ilustrada. Disponível em: <http://www1.folha.uol.com.br/folha /ilustrada/ult90u58337.shtml>. Acesso em: 19 maio 2008.

MANN, William. Bastidores de Hollywood: a influência exercida por gays e lésbicas 1910 1969. São Paulo: Landscape, 2002. 442 p.

MARCUSE, Herbert. Eros e civilização. Rio de Janeiro: Zahar, 1981. 232 p.

MARCUSE, Herbert. Ideologia da sociedade industrial. Rio de Janeiro: Zahar, 1967. 238 p.

MICHAEL. Gay-Themed Films of the German Silent Era. Kino Vídeo, 2004. DVD.

MORENO, Antônio. A personagem homossexual no cinema brasileiro. Rio de Janeiro: EDUFF, 2001. 307 p.

NAZARIO, Luiz. Monstros marcianos. In: JEHA, Julio (Org.). Monstros e monstruosidades na literatura. Belo Horizonte: FALE/UFMG, 2007. p. 146-183.

NAZARIO, Luiz. Todos os corpos de Pasolini. São Paulo: Perspectiva, 2007. 400 p.

OTTOSSON, Daniel. Homofobia no Estado: uma pesquisa mundial sobre legislações que pró́bem relação sexual consensual entre adultos homossexuais; um relatório da ILGA (International Lesbian and Gay Association). abr. 2007. Disponível em: < http://www.ilga.org/ statehomophobia/Homofobia_do_Estado_ILGA_07.pdf.> Acesso em: 17 maio 2007. 
PIRES, Thereza. Sexo, mentiras e Hollywood: o Código de Hays. Mix Brasil, 16 jul. 2003. Disponível em: <http://mixbrasil.uol.com.br/cultura/especiais/codigo/codigo.asp >. Acesso em: 27 jun. 2008.

PIRES, Thereza. Tab Hunter: Antes tarde do que nunca. Mix Brasil, 20 jul. 2007. Disponível em: <http://mixbrasil.uol.com.br/mp/upload/noticia/3_52_61515.shtml>. Acesso em: 19 maio 2008.

SALOMÉ. Texto do encarte de Lori Martin. DVD produzido por David Shepard. Image Entertainment, 2001. DVD.

SEX in Chains. Gay Themed Films of the German Silent Era. Restored by Film Museum München. Kino Vídeo, 2004. DVD.

SULLIVAN, Andrew. Praticamente normal: uma discussão sobre o homossexualismo. São Paulo: Companhia das Letras, 1996. 173 p. 